\title{
Purification, Characterization and Immunological Properties of the Serotype-specific Capsular Polysaccharide of Pasteurella haemolytica (Serotype A1) Organisms
}

\author{
By C. ADLAM, ${ }^{1 *}$ J. M. KNIGHTS, ${ }^{1}$ ANNE MUGRIDGE, ${ }^{1}$ J. C. LINDON, ${ }^{2}$ \\ P. R. W. BAKER, ${ }^{2}$ J. E. BEESLEY, ${ }^{1}$ BETTY SPACEY, ${ }^{3}$ G. R. CRAIG ${ }^{3}$ \\ AND L. K. NAGY ${ }^{1}$ \\ Departments of ${ }^{1}$ Bacteriology, ${ }^{2}$ Physical Chemistry and ${ }^{3}$ Veterinary Biology, \\ The Wellcome Research Laboratories, Beckenham, Kent, UK
}

(Received 13 March 1984; revised 16 May 1984)

\begin{abstract}
The serotype-specific capsular polysaccharide from two strains of Pasteurella haemolytica serotype A1 organisms was purified and characterized by chemical analysis and NMR spectroscopy. The polymer has the structure $\rightarrow 3)-O$-(2-acetamido-2-deoxy-4- $O$-acetyl- $\beta$-Dmannopyranosyluronic acid)-(1 $\rightarrow 4)-O$-(2-acetamido-2-deoxy- $\beta$-D-mannopyranose $)-(1 \rightarrow$. The polysaccharide was immunogenic (able to evoke production of antibodies) for sheep but not for rabbits. Immuno electron-microscopy studies using the Protein A-gold technique showed the polysaccharide to be peripherally located on the bacterial surface. Reduction, oxidation and de$O$-acetylation of the polymer did not appear to alter its immunological precipitability with specific antiserum, but all three treatments destroyed its ability to adhere to sheep erythrocytes at neutral $\mathrm{pH}$. De- $N$-acetylation of the polymer destroyed both immunological precipitability and erythrocyte adherence.
\end{abstract}

\section{INTRODUCTION}

Pasteurella haemolytica organisms may be separated by antibiotic resistance, biochemical fermentation and colonial morphology into two biotypes, $A$ and $T$, consisting of 15 serotypes (Fraser et al., 1982). One of these serotypes, the A1, is associated with outbreaks of 'shipping fever', a respiratory disease of considerable economic importance which occurs in feed-lot cattle in North America. It is also associated with a minority (approx. 7\%, Fraser et al., 1982) of outbreaks of pasteurellosis in lambs in Great Britain.

The bacterial capsular substance is responsible for serological specificity and is presumed to play a role in the pathogenicity of the organism. The present paper describes the purification, structure and location of the Al serotype capsular antigen of two strains of $P$. haemolytica. The effects of chemical treatment of the antigen on its immunological reactivity with specific antiserum and on its ability to adhere to sheep erythrocytes were also investigated.

\section{METHODS}

Bacterial strains and growth conditions. The two Al serotype strains used were maintained as freeze dried cultures in the Wellcome Culture Collection. They were CN5730 (originally obtained from the Moredun Institute, Edinburgh, UK, as strain B636) and P1075, isolated from the nasal cavity of a calf at necropsy at Ames, Iowa, USA.

\footnotetext{
Abbreviations: CAP, crude acetone precipitate; EPP, ethanol-purified precipitate; GlcNAc, 2-acetamido-2deoxyglucose ( $N$-acetylglucosamine); GalNAc, 2-acetamido-2-deoxygalactose; ManNAc, 2-acetamido-2deoxymannose; ManNAcA, 2-acetamido-2-deoxymannuronic acid; GalNAcA, 2-acetamido-2deoxygalacturonic acid; GlcNAcA, 2-acetamido-2-deoxyglucuronic acid.
} 


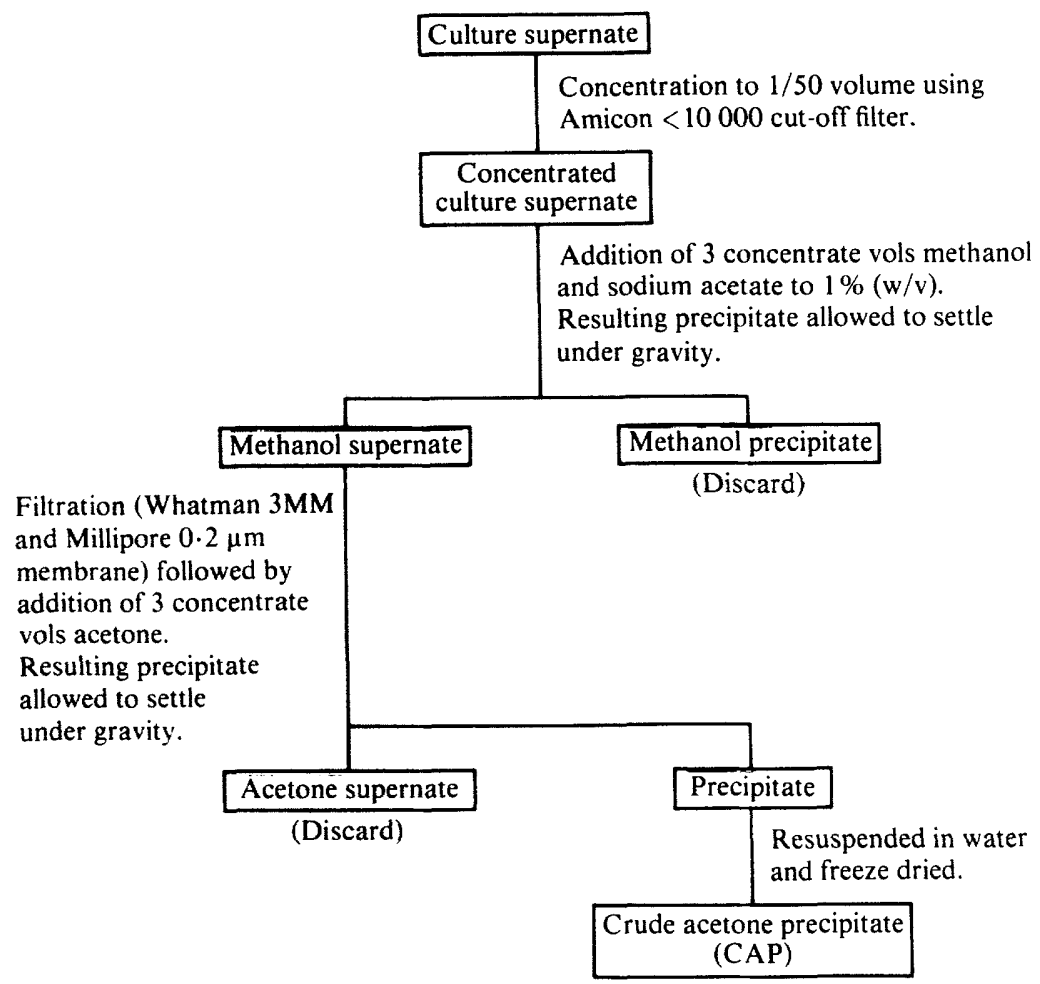

Fig. 1. Partial purification of crude capsular polysaccharide from culture supernates.

Prior to growth in bulk, irridescent colonies were selected from dextrose starch agar (Difco) plates and grown statically at $37^{\circ} \mathrm{C}$ in small volumes of Pasteurella broth no. 7 (Wellcome). Following sub-inoculation, organisms were grown with slow stirring in 200-litre steel fermenters containing Pasteurella broth. Cultures were aerated at $701 \mathrm{~min}^{-1}$ and $\mathrm{pH}$ was controlled by addition of $\mathrm{KOH}$ to between $\mathrm{pH} 7.2$ and 7.4 during incubation for $10 \mathrm{~h}$ at $37^{\circ} \mathrm{C}$. The $\mathrm{OD}_{650}^{1} \mathrm{~cm}$ of the final organism suspension was 13.4 for CN5730 and 10.0 for P1075.

Preparation of crude capsular polysaccharide. Preliminary purification was based on the method used by Penn \& Nagy (1976) for purifying capsular polysaccharides from Pasteurella multocida serotypes B and E. Cultures were heated $\left(60^{\circ} \mathrm{C}\right.$ for $\left.1 \mathrm{~h}\right)$ and $0.2 \%(\mathrm{v} / \mathrm{v})$ formalin was added. Organisms were removed by centrifugation $(9500 \mathrm{~g}, 1 \mathrm{~h}$, $4^{\circ} \mathrm{C}$ ) and the culture supernate treated as described in Fig. 1.

Preparation of purified capsular polysaccharide. Crude acetone precipitate (CAP) was further purified by the method of Gotschlich et al. (1972), according to the protocol described in Fig. 2.

Saline extraction. Crude saline extracts of whole organisms were made from cultures grown on sheep blood agar $\left(18 \mathrm{~h}\right.$ incubation at $\left.37^{\circ} \mathrm{C}\right)$ by washing off the growth into saline $\left(0.85 \%, \mathrm{w} / \mathrm{v} ; 2 \mathrm{ml}\right.$ per plate) and heating at $56^{\circ} \mathrm{C}$ for $1 \mathrm{~h}$. After incubation, bacterial cells were removed by centrifugation $(2000 \mathrm{~g}, 15 \mathrm{~min}$ at room temperature $)$ and the undiluted supernate used in immunodiffusion and passive haemagglutination experiments.

Sodium salicylate extraction. Whole washed organisms were extracted with sodium salicylate $(1.0 \mathrm{M})$ by incubation at $37^{\circ} \mathrm{C}$ for $3 \mathrm{~h}$ (Gilmour et al., 1979). After extraction the cells were removed by centrifugation $\left(2800 \mathrm{~g}, 40 \mathrm{~min}, 4^{\circ} \mathrm{C}\right.$ ) and the supernate was dialysed against distilled water prior to freeze drying.

De-O-acetylation. $O$-acetyl groups were removed from the purified polymer by the method of Bhattacharjee $e t a l$. (1975). In brief, the polymer was treated with $0.1 \mathrm{M}-\mathrm{NaOH}$ for $4 \mathrm{~h}$ at $37^{\circ} \mathrm{C}$ prior to neutralization with acetic acid, dialysis against distilled water and freeze drying.

De- $N$-acetylation. $N$-Acetyl and $O$-acetyl groups were removed by the method of Kenne \& Lindberg (1980). In brief, the polymer was treated with $\mathrm{NaOH}$, benzenethiol and dimethyl sulphoxide and the stirred mixture heated under nitrogen in a sealed tube at $100^{\circ} \mathrm{C}$ for $6.5 \mathrm{~h}$ prior to dialysis against distilled water and freeze drying.

Periodate treatment. Oxidation of the purified polymer was attempted using sodium metaperiodate $(0.075 \mathrm{M})$ (Spiro, 1966); consumption of periodate in the reaction was followed using the optical method of Dixon \& Lipkin (1954). 


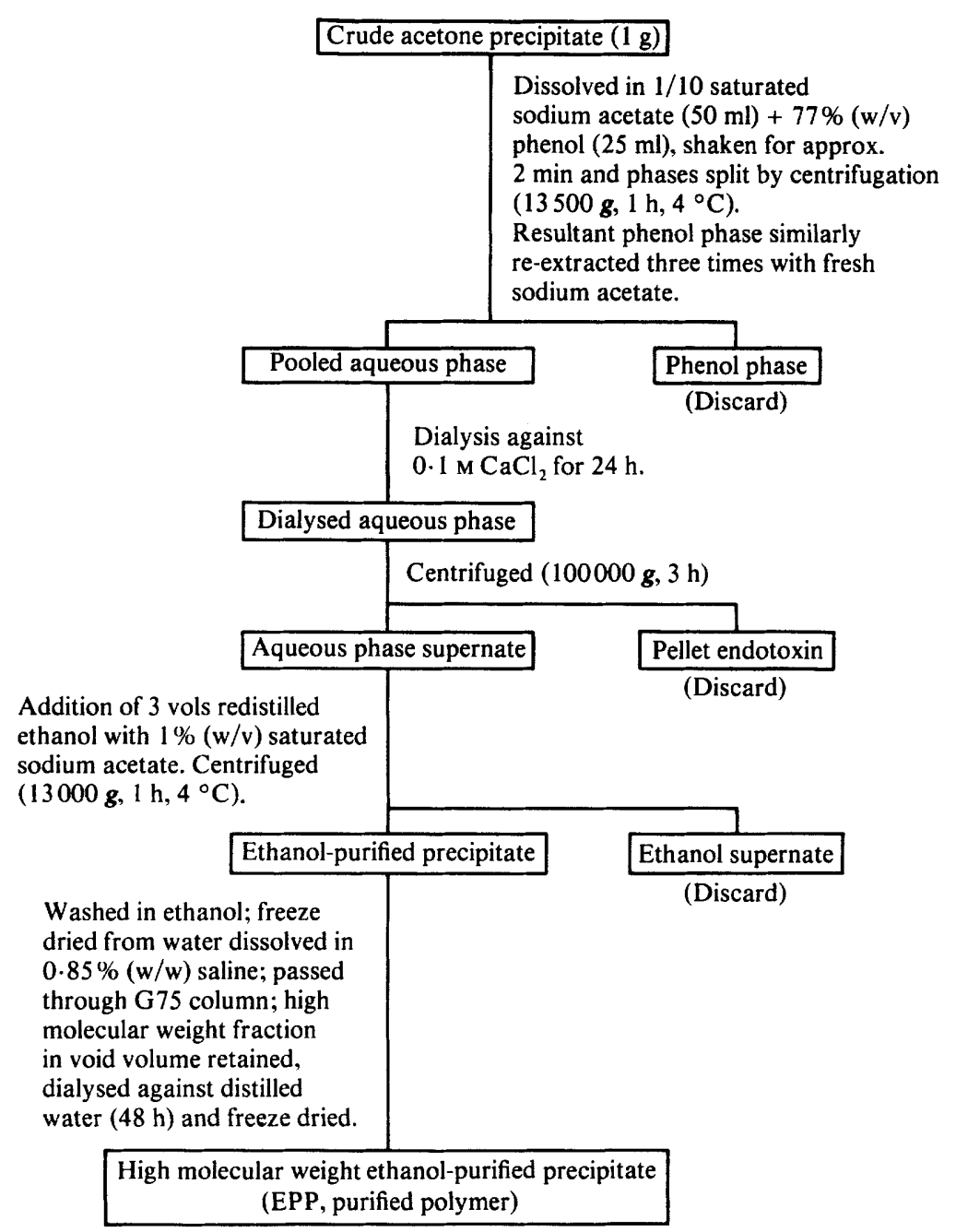

Fig. 2. Further purification of capsular polysaccharide from crude precipitate.

Reduction of the polymer. The purified polymer was reduced by three cycles of treatment with 1-ethyl-3-(3dimethylaminopropyl)carbodi-imide and sodium borohydride (Taylor \& Conrad, 1972). The reduced polymer was dialysed against distilled water and freeze dried.

Deamination of component sugars. The purified polymer was hydrolysed $\left(6 \mathrm{M}-\mathrm{HCl}, 100^{\circ} \mathrm{C}, 18 \mathrm{~h}\right)$ and the freezedried hydrolysate treated with nitrous acid by the method of Horton et al. (1972). In brief, the hydrolysate was treated with sodium nitrite and acetic acid at $0{ }^{\circ} \mathrm{C}$. Following freeze drying, methanol was added and the resultant precipitate analysed colorimetrically for D-glucose using D-glucose oxidase (Sigma test kit).

Ninhydrin degradation. The purified polymer was hydrolysed in a sealed ampoule with $6 \mathrm{M}-\mathrm{HCl}$ for $18 \mathrm{~h}$ at $100^{\circ} \mathrm{C}$. The filtered hydrolysate was dried, resuspended in water and treated with ninhydrin by the method of Stoffyn \& Jeanloz (1954). Sugars resulting from this degradation were analysed by thin layer chromatography on Whatman LK 5D Linear-K Silica gel ( $80 \mathrm{~A}$ ) plates. The solvent system used was $1 \mathrm{M}$-lactic acid/acetone/propan-2ol $(2: 4: 4$, by vol.). The chromatogram was developed by dipping in the aniline/diphenylamine/acetone/80\% $(\mathrm{v} / \mathrm{v})$ phosphoric acid $(4 \mathrm{ml}: 4 \mathrm{~g}: 200 \mathrm{ml}: 30 \mathrm{ml})$ reagent of Hansen $(1975)$ and heating to $100^{\circ} \mathrm{C}$ for $10 \mathrm{~min}$.

Amino-acid analysis. Samples were hydrolysed in sealed ampoules with $6 \mathrm{M}-\mathrm{HCl}$ for $18 \mathrm{~h}$ at $100^{\circ} \mathrm{C}$. The filtered hydrolysate was dried, re-suspended in water and analysed on a Beckman 120B amino-acid analyser using a Beckman M72 column. The column was eluted using two $0.07 \mathrm{M}$-sodium citrate/ $\mathbf{H C l}$ buffers at $\mathrm{pH} 3.25$ for acidic components and $\mathrm{pH} 4 \cdot 3$ for basic components. Peaks were visualized with ninhydrin after elution.

Infra-red analysis. Solid samples were dispersed in standard $16 \mathrm{~mm}$ diameter $\mathrm{KBr}$ discs by grinding 
approximately $1 \mathrm{mg}$ sample with $350 \mathrm{mg} \mathrm{KBr}$ in a ball mill. Analysis was done in a Perkin Elmer 580 spectrometer over the range $400-4000 \mathrm{~cm}^{-1}$

High pressure liquid chromatography $(H P L C)$. Samples of purified polymer were hydrolysed in sealed ampoules with $6 \mathrm{M}-\mathrm{HCl}$ for $18 \mathrm{~h}$ at $100^{\circ} \mathrm{C}$. The filtered hydrolysate was dried and dissolved in distilled water prior to analysis in acetonitrile/water $(84: 16, \mathrm{v} / \mathrm{v})$ using a Zorbax $-\mathrm{NH}_{2}$ column (Dupont) on an HPLC system (Laboratory Data Control, Stone, Staffs., UK). Peaks were detected by absorbance at $200 \mathrm{~nm}$ in a spectromonitor III detecter using Constametric III pumps (Laboratory Data Control) and a flow rate of $4 \mathrm{ml} \mathrm{min}^{-1}$.

Nuclear magnetic resonance $(N M R)$ spectroscopy. Samples were dissolved in a $\mathrm{D}_{2} \mathrm{O}$ solution and natural abundance ${ }^{13} \mathrm{C}$ spectra measured at $90.5 \mathrm{MHz}$ and 100.6 MHz using Bruker WM-360 and WM-400 spectrometers. The ' $\mathrm{pH}$ ' of the purified polymer in $\mathrm{D}_{2} \mathrm{O}$ was 6.3. Spectra were obtained at ambient temperatures using $5 \mathrm{~mm}$ sample tubes, employing ' $\mathrm{H}$ broad-band decoupling. The distinction between methyl, methylene, methine and quaternary carbons was obtained through the use of the 'inter nuclear excitation by polarization transfer' (INEPT) pulse sequence (Morris \& Freeman, 1979), which also yielded the one bond ${ }^{13} \mathrm{C}-{ }^{1} \mathrm{H}$ coupling constants for the anomeric carbons. With the essentially non-existent field instability of superconducting magnet NMR spectrometers it is quite feasible to use a separate sample of a known material to set up and calibrate an externally referenced chemical shift scale. This was done for the present samples using dioxan in $\mathrm{D}_{2} \mathrm{O}$, the ${ }^{13} \mathrm{C}$ chemical shift of which was taken at 67.4 p.p.m. to high frequency of tetramethylsilane, the usual primary reference. This enabled the unambiguous assignment of the various regions of the spectrum, for example the $N$-acetyl methyl resonances. However, to obtain the greatest reproducibility between samples, the chemical shifts of the $N$-acetyl methyl signals were taken at $24 \cdot 7$ p.p.m., based upon previous reports which showed that they fall in a very narrow range and are unaltered by medium effects. For example, taking the shift of the $N$-acetyl methyl signal to be the same as that in the Micrococcus luteus polysaccharide will only introduce a $0 \cdot 1$ p.p.m. change in chemical shifts (Bundle et al., 1973; Johnson et al., 1981; Jansson et al., 1981; Gorin, 1981; Tsui et al., 1981 a, 1982; Perry et al., 1981). Pulse widths of approximately $60^{\circ}$ were used. ${ }^{1} \mathrm{H}$ NMR spectra were measured under similar conditions at $90.0 \mathrm{MHz}$ and $360 \mathrm{MHz}$ using Bruker HFX-90 and WM-360 spectrometers in the pulse-FT mode.

Electron microscopy. Bacteria were grown overnight at $37^{\circ} \mathrm{C}$ on sheep blood agar and were scraped off the plate with a glass coverslip. Fixation was carried out at room temperature in $2.5 \%(\mathrm{v} / \mathrm{v})$ glutaraldehyde in $0.1 \mathrm{M}-$

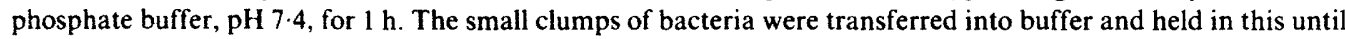
embedding in glycol methacrylate containing 3\%(v/v) $n$-butyl methacrylate (Emscope Laboratories, Ashford, Kent. UK). Gold-coloured sections were cut with an Ultratome III (LKB) onto Butvar-coated 4000 gold grids.

Immunohistochemical labelling of capsular antigen was carried out using the Protein A-gold method (Beesley et al., 1982). The sections were incubated in serial tenfold dilutions of antibody overnight, washed for 5 min in running tap water, and then incubated for $1 \mathrm{~h}$ in the Protein $\mathrm{A}$-gold complex. After a thorough washing in tap water, the sections were dried and finally exposed to osmium vapour for $30 \mathrm{~min}$ to increase contrast.

The antibody used was prepared in a sheep (see below) using purified polymer.

All specimens were examined in a Philips 300 transmission electron microscope operating at $80 \mathrm{kV}$.

Chemical analysis. Phosphorus was sought following sulphuric acid decomposition $\left(3 \mathrm{~h}, 420^{\circ} \mathrm{C}\right)$ of the purified polymer and precipitation with ammonium molybdate. Neutral sugars were assayed by the anthrone/sulphuric acid method (Roe, 1955) and by the phenol/sulphuric acid method (Dubois et al., 1956). Hexosamines were assayed by the method of Lane Smith \& Gilkerson (1979) and hexuronic acids by the carbazole/sulphuric acid method of Dische (1947). Sialic acids were sought by the thiobarbituric acid method of Warren (1959) and the resorcinol method of Svennerholm (1957). Protein was sought by the method of Lowry and by the Bio-Rad protein assay. O-Acetyl groups were assayed by the method of Hestrin (1949) using an acetylcholine chloride standard.

Optical rotation measurements. These were carried out using a Bellingham and Stanley model D polarimeter with a path length of $2 \mathrm{dm}$.

Molecular weight determination. An approximate molecular weight of the purified polymer was determined using a $90 \mathrm{~cm} \times 1.6 \mathrm{~cm}$ column of Sepharose 2B (Pharmacia) and a blue dextran (2000) standard of mean molecular weight $2 \times 10^{6}$. The polymer was eluted with $0.85 \%(\mathrm{w} / \mathrm{v})$ saline and detected by measuring absorbance at $206 \mathrm{~nm}$ in an LKB Uvicord ' $S$ ' spectrophotometer.

Production of antiserum. Rabbit antisera were raised against whole organisms by multiple twice weekly intravenous injections of washed formalin-treated cells $\left(O D_{650}^{1} \mathrm{~cm}=0.38\right)$ previously grown on sheep blood agar plates and suspended in saline $(0.85 \%, \mathrm{w} / \mathrm{v})$. Doses were gradually increased from $0.5 \mathrm{ml}$ to $3 \mathrm{ml}$ over 3 weeks. Animals were bled $10 \mathrm{~d}$ after the last injection.

Sheep antisera were raised against purified polymer by intraperitoneal injection of $5 \mathrm{mg}$ antigen, emulsified in incomplete Freund adjuvant (Wellcome). The antigen was dissolved in 3 parts of saline containing $2 \%(\mathrm{v} / \mathrm{v})$ Tween 80 (Difco) prior to emulsification in 7 parts of oil phase. Sheep were bled 3-4 weeks after a single injection.

Immunodiffusion. Immunodiffusions were done on glass slides $(5 \times 5 \mathrm{~cm})$ covered with $3.3 \mathrm{ml} 1 \%(\mathrm{w} / \mathrm{v})$ agarose (Sigma, Type I) in saline $(0.85 \%$,w/v). Six peripheral wells $(5 \mathrm{~mm}$ diameter) were cut $5 \mathrm{~mm}$ away from a central well $(7 \mathrm{~mm}$ diameter). Samples $(30 \mu \mathrm{l})$ of antigens dissolved in saline were applied to the peripheral wells, and undiluted antiserum $(50 \mu \mathrm{l})$ to the central well. Immunoprecipitation lines were recorded after slides had been allowed to stand overnight at room temperature. 
Passive haemagglutination. Sheep erythrocytes were washed on saline $(0.85 \%, w / v)$ and sensitized with bacterial extracts for $2 \mathrm{~h}$ at $37^{\circ} \mathrm{C}$. Packed cells $(100 \mu \mathrm{g})$ were sensitized with $10 \mathrm{ml}$ of extract $\left(0 \cdot 1 \mathrm{mg} \mathrm{ml}^{-1}\right)$. Sensitized cells were washed three times in saline and re-suspended to a final concentration of $0.5 \%(\mathrm{v} / \mathrm{v})$ packed cells. For antiserum titrations, doubling dilutions of sera in saline were made in V-shaped wells of microtitre trays (Sterilin) and an equal volume $(50 \mu \mathrm{l})$ of sensitized cells was added. After mixing, trays were left at room temperature for $18 \mathrm{~h}$. End points were recorded as the reciprocal of the last well showing haemagglutination.

Pyrogenicity for rabbits. Groups of three New Zealand male white rabbits (Ranch rabbits, Copthorne, Surrey, UK) weighing 2-3 kg received intravenous injections of graded doses of extracts dissolved in saline $(0 \cdot 85 \%, w / v)$. Rectal temperatures were recorded by thermocouple for $2 \mathrm{~h}$ prior to injection and for $6 \mathrm{~h}$ after injection.

Limulus lysate assay. The ability of purified polymer to cause gelation of Limulus amoebocyte lysate was assessed using the Mallinckrodt test kit (Mallinckrodt Inc., St Louis, Mo., USA). This test is used to detect endotoxin and compares the gelling ability of dilutions of test substances in pyrogen free saline $(0.85 \%$, w/v) with that produced by dilutions of a standard Escherichia coli endotoxin preparation. Gelation was recorded $75 \mathrm{~min}$ after mixing the samples and lysate together and incubating at $37^{\circ} \mathrm{C}$.

Chick embryo toxicity. Twelve-day-old chick embryos were injected intravenously with dilutions of extracts in saline $(0.85 \%, w / v)$. Deaths were recorded at $24 \mathrm{~h}$ by observing the embryos with the aid of a light box.

\section{RESULTS}

Yield of extract antigens. Using the purification method described (Fig. 1), the yield of CAP per litre of culture supernate was $0.68 \mathrm{~g}$ for CN5730 and $0.75 \mathrm{~g}$ for P1075. When this was further purified (Fig. 2), yields of EPP were $39.5 \%$ (by weight) of the CAP for CN5730 (one experiment) and $40.2 \%$ and $47 \cdot 1 \%$ for P1075 (two experiments). The high molecular weight fraction (purified polymer) was prepared from P1075 only, and this accounted for $79.6 \%$ of EPP (or $32 \%$ of CAP). No attempt was made in these experiments to optimize yields of these antigens by, for example, alteration of bacterial growth conditions.

Physical characteristics. The purified polymer was a white powder, freely soluble in water with a specific optical rotation $[\alpha]_{D}^{20}$ of $-46 \cdot 2^{\circ} \pm 2.5^{\circ}$ in water at a concentration of $2.08 \%(\mathrm{w} / \mathrm{v})$. The molecular weight was in excess of $4 \times 10^{6}$.

Chemical analysis. Chemical analysis of the purified polymer revealed the absence of phosphorus $(<0 \cdot 1 \%$, by weight), of protein $(<1 \%$, by weight), when analysed by both methods described with BSA as standard, and of hexose $(<1 \%$, by weight), using the phenol sulphuric acid assay with glucose as standard. Assay for hexose by the anthrone method gave $6 \%$ by weight. Sialic acids and pentoses were absent $(<1 \%$, by weight) with $N$-acetyl neuraminic acid and arabinose as standards, respectively. The hexuronic acid assay gave a value of $2.5 \%$, by weight, with glucuronic acid as a standard. Hexosamine determinations on samples hydrolysed under optimal conditions $\left(6 \mathrm{M}-\mathrm{HCl}, 18 \mathrm{~h}, 100^{\circ} \mathrm{C}\right)$ gave a value of $46.6 \%$, by weight, as hexosamine. Purified polymer reduced by treatment with carbodi-imide and sodium borohydride gave a value of $61.0 \%$, by weight, as hexosamine. Both determinations were compared to a 2-amino-2-deoxymannose standard. Assay for $O$-acetyl content gave a value of $7.4 \%$, by weight. When purified polymer was treated with sodium metaperiodate, no periodate uptake was detected.

Amino acid analysis. A sample of purified polymer prepared from P1075 and hydrolysed with $6 \mathrm{M}-\mathrm{HCl}$ for $18 \mathrm{~h}$ at $100^{\circ} \mathrm{C}$ gave (apart from ammonia, which was the last peak to elute) two major peaks when analysed on an amino acid analyser (Fig. $3 a$ ). Of these peaks, one (peak 1) had an identical retention time (56 min after buffer change) to a 2-amino-2-deoxymannose standard and this could be differentiated from both 2-amino-2-deoxyglucose $(40 \mathrm{~min})$ and 2 amino-2-deoxygalactose $(60 \mathrm{~min})$ standards. The other peak (peak $2 ; 125 \mathrm{~min}$ ) could not be identified using available standards. When less severe hydrolytic conditions were used $(0.1 \mathrm{M}$ $\mathrm{HCl}$ for $12 \mathrm{~h}$ at $100^{\circ} \mathrm{C}$ ), four peaks were observed, two of these being the same as those present in the more vigorously hydrolysed sample (Fig. $3 b$ ). The ratio of the peak height for the 2-amino-2deoxymannose peak (1) compared to unknown peak (2) was $1: 0.23$ for hydrolysis with $6.0 \mathrm{M}$ $\mathrm{HCl}$ for $18 \mathrm{~h}$, and $1: 1.87$ for hydrolysis with $0 \cdot 1 \mathrm{M}-\mathrm{HCl}$ for $12 \mathrm{~h}$. When the reduced polymer was hydrolysed $(6.0 \mathrm{M}-\mathrm{HCl}$ for $18 \mathrm{~h}$ or $2.0 \mathrm{M}-\mathrm{HCl}$ for $4 \mathrm{~h})$ and the hydrolysate analysed, it was noticeable that the unknown peak 2 was reduced to a trace amount when compared to that seen with a similar hydrolysate from the non-reduced polymer. 


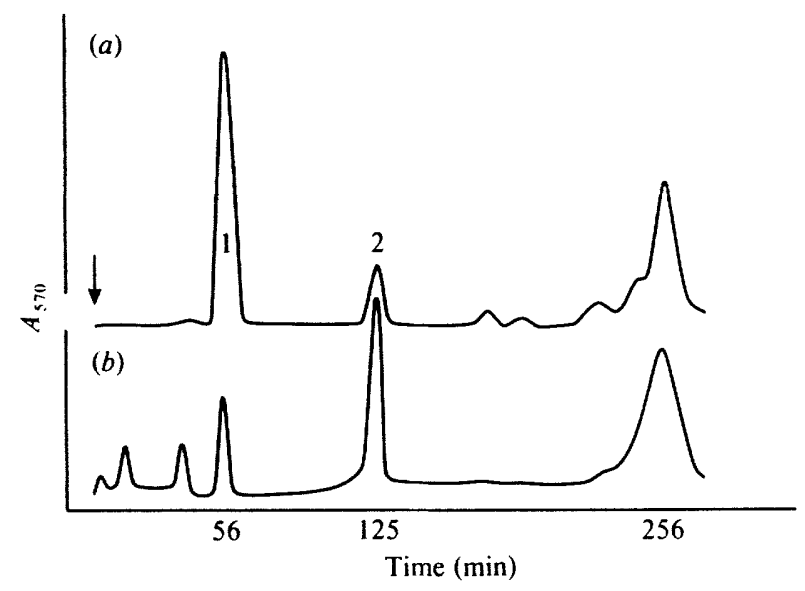

Fig. 3. Amino acid analysis of hydrolysates of purified polymer prepared from strain P1075. (a) Hydrolysed with $6.0 \mathrm{M}-\mathrm{HCl}$ for $18 \mathrm{~h}$ at $100^{\circ} \mathrm{C} ;\left(\right.$ b) hydrolysed with $0.1 \mathrm{M}-\mathrm{HCl}$ for $12 \mathrm{~h}$ at $100^{\circ} \mathrm{C}$. The arrow indicates the point of application of the second buffer ( $\mathrm{pH} 4 \cdot 3$ ). No peaks were eluted using the first acidic buffer.

HPLC. Hydrolysed purified polymer gave rise to a major peak with an identical retention time to a standard sample of 2-amino-2-deoxymannose (Sigma). This sugar could be differentiated from 2-amino-2-deoxyglucose and 2-amino-2-deoxy-galactose standards.

NMR spectroscopy. The ${ }^{13} \mathrm{C}$ NMR spectrum of the purified polymer showed, apart from signals due to acetyl groups, 12 peaks indicating a two-sugar repeating unit. Of these 12 signals, one appeared at 176.4 p.p.m., consistent with a carboxyl group. In addition, two signals appeared in the 50-60 p.p.m. range, characteristic of amino-sugar-CH-NH-resonances. It was concluded, therefore, that the repeating unit was a disaccharide consisting of an amino sugar and an aminouronic acid. Double-intensity peaks appeared at 24.7 p.p.m. and 177.4 p.p.m., confirming that both amino groups were $N$-acetylated. In addition, peaks were detected at 23.2 p.p.m. and 175.2 p.p.m., consistent with a single $O$-acetyl group. The ${ }^{1} \mathrm{H}$ NMR spectrum also showed three acetyl methyl resonances, confirming the presence of the three acetyl groups in the repeating unit. One ${ }^{13} \mathrm{C}$ peak was observed at 62.9 p.p.m. The INEPT experiment showed this to be due to a methylene carbon and this was thus assigned to the $\mathrm{C} 6$ of the hexosamine; the peak position indicated that linkage was not through C6. Thus for both sugar units, the linkage must be through $\mathrm{C} 3$ or $\mathrm{C} 4$.

Amino analysis and HPLC showed that the hexosamine in the acid-hydrolysed (and hence de$O$-acetylated) polymer was probably 2-amino-2-deoxymannose. The INEPT experiment gave a one-bond carbon-hydrogen coupling for the two anomeric carbons as $162-163 \mathrm{~Hz}$, indicating a $\beta$ linkage for at least this sugar (Bundle et al., 1973; Jansson et al., 1981; Tsui et al., 1981 a).

The identification of the $N$-acetylhexosamine as ManNAc was supported by the predicted and observed shifts for $\mathrm{Cl}$ of $\beta$-GlcNAc and $\beta$-GalNAc, linked either through $\mathrm{C} 3$ or $\mathrm{C} 4$ (Bundle et al., 1973; Gorin, 1981). For example, in the Haemophilus influenzae type $\varepsilon$ polysaccharide containing $\rightarrow 3)-\beta$-GlcNAc- $(1 \rightarrow$ this unit has a $C 1$ shift of 103.1 p.p.m., and a C2 shift of 57.5 p.p.m. (Tsui et al., 1981 a). In addition, the $\mathrm{Cl}$ shifts showed both sugars to be pyranose rather than furanose (Bock \& Thøgerson, 1982).

In order to confirm both sugar types, the ${ }^{1} \mathrm{H}$ NMR spectrum of the de $O$-acetylated polysaccharide was measured. Examination of the spectrum showed that both of the anomeric protons appeared as singlets with no resolved couplings due to other protons, and that both of the $\mathrm{C}_{2}-\mathrm{H}_{2}$ signals appeared as doublets of about $4-5 \mathrm{~Hz}$ caused by coupling to $\mathrm{H}_{3}$. Since the ${ }^{13} \mathrm{C}$ INEPT results had indicated that both sugars were $\beta$-linked, it was possible to compare the $\mathrm{H}_{1}-$ $\mathrm{H}_{2}$ and $\mathrm{H}_{2}-\mathrm{H}_{3}$ coupling constants for the sugars in the polymer with those of an authentic sample of ManNAc (Sigma) and published values (Bock \& Thøgerson, 1982) for $\beta$-gluco-, $\beta$ - 
galacto- and $\beta$-manno- compounds. Values for $\mathrm{H}_{1}-\mathrm{H}_{2}$ coupling constants in $\mathrm{Hz}$ were 8.4 for $\beta$ gluco-, 8.4 for $\beta$-galacto- and 1.5 for $\beta$-manno-. Values for $\mathrm{H}_{2}-\mathrm{H}_{3}$ constants were $9.6,10.5$ and $4 \cdot 5$, respectively. The observed values for the polymer sugars were $<2 \mathrm{~Hz}$ for $\mathrm{H}_{1}-\mathrm{H}_{2}$ and in the 4-5 $\mathrm{Hz}$ range for $\mathrm{H}_{2}-\mathrm{H}_{3}$, thus confirming the manno- configuration for both component sugars.

Thus this experiment also identified the uronic acid as 2-acetamido-2-deoxymannuronic acid, and from the INEPT value for $\mathrm{J}(\mathrm{C} 1-\mathrm{H} 1)$, both sugars were manno- and $\beta$-linked, with the sugars linked to each other either at $\mathrm{C} 3$ or $\mathrm{C} 4$. It should be pointed out that the ${ }^{1} \mathrm{H}$ NMR results only define the configuration at $\mathrm{Cl}$ and $\mathrm{C} 2$, and hence the presence of the alternative rare sugars (2acetamido-2-deoxyidose, 2-acetamido-2-deoxytalose and 2-acetamido-2-deoxyaltrose) cannot be ruled out (Goustin et al., 1983). For this reason, ninhydrin degradation of the putative 2amino-2-deoxymannose was carried out and the resultant substances analysed by thin layer chromatography by comparison with breakdown products obtained with an authentic sample of 2-amino-2-deoxymannose and with candidate pentose breakdown products. Both polymerderived and authentic 2-amino-2-deoxymannose-derived samples gave rise to purple staining spots of $R_{F}(0.48)$ identical to that of an arabinose standard. Also both gave rise to green staining spots of identical $R_{F}(0.62)$. These were probably a ninhydrin/hexosamine intermediate, as described by Stoffyn \& Jeanloz (1954).

Since only 2-amino-2-deoxyglucose and 2-amino-2-deoxymannose can give rise to arabinose following ninhydrin degradation (Gardell et al., 1950), and since the presence of the former sugar was excluded by NMR data as well as other analytical techniques described, the identity of the hexosamine and aminohexuronic acid in the polymer as manno- sugars was confirmed. Additional confirmation was afforded by deaminating the component sugars of the polymer with nitrous acid (Horton et al., 1972). D-Glucose was detected as one of the products of this reaction by use of $\mathrm{D}$-glucose oxidase.

Examination of the borohydride reduced polysaccharide showed that the polymer was not a simple homopolymer of 2-amino-2-deoxy mannose, and hence the two sugars must be linked differently. The only possibilities were:

$$
\begin{aligned}
& \rightarrow 3)-\operatorname{ManNAc}-(\beta 1 \rightarrow 4)-\operatorname{ManNAcA}-(\beta 1 \rightarrow \\
& \rightarrow 4)-\operatorname{ManNAc}-(\beta 1 \rightarrow 3)-M a n N A c A-(\beta 1 \rightarrow
\end{aligned}
$$

The position of $O$-acetylation was found to be at a $\mathrm{C} 4$ position because of the lack of shift of either $\mathrm{C} 2$ on de- $O$-acetylation (see Table 1). Comparison of the spectra of $O$-acetyl and de- $O$ acetyl polymers showed that two signals moved to higher frequency (lower field) and one moved in the opposite direction. From the known substituent effects it was clear that this latter signal at 70.0 p.p.m. in the de $O$-acetyl polysaccharide arose from $\mathrm{C} 4$ of the unit linked at $\mathrm{C} 3$, and that the other signals which shift (79.5 and 79.8 p.p.m. in the de- $O$-acetyl material) were due to the $\mathrm{C} 3$ and $\mathrm{C} 5$ resonances of the same ring. This shift for $\mathrm{C} 5$ cannot arise in a C3-linked ManNAc unit (Bundle et al., 1975) and was therefore from the 2-acetamido-2-deoxymannuronic acid moiety, where the shift fitted perfectly for a C3-linked unit. This assignment was reinforced by the values for the $\mathrm{Cl}$ carbons. From previously published data, the $\mathrm{Cl}$ chemical shifts for structure (I) above would be $>100.5$ and approx. 102 p.p.m. (Bennett \& Bishop, 1980; Johnson et al., 1981), whereas for the alternative structure (II) the predicted shifts would be approx. 98 and 100.5 p.p.m. (Jansson et al., 1981; Tsui et al., 1981 b), very close to the observed values.

When the ${ }^{13} \mathrm{C}$ spectrum of the reduced polymer was compared with that of the original purified polymer, the $O$-acetyl resonances and the peak due to the carboxyl carbon were lost. The signal due to the $\mathrm{CH}_{2} \mathrm{OH}$ group at the $\mathrm{C} 6$ of ManNAc in the original polymer was doubled in intensity for the reduced polymer, confirming that reduction of the carboxyl group of ManNAcA to $-\mathrm{CH}_{2} \mathrm{OH}$ had taken place.

The final ${ }^{13} \mathrm{C}$ assignments are given in Table 1.

The negative value obtained for the specific optical rotation of the polymer (see above) and the finding that both component sugars were $\beta$-linked strongly suggested that both sugars were in the $\mathrm{D}$ configuration. This was confirmed by the demonstration, using $\mathrm{D}$-glucose oxidase, that D-glucose resulted from deamination of the polymer hydrolysate. 
Table $1 .{ }^{13} \mathrm{C} N M R$ parameters for the native and de-O-acetylated purified polymer

\begin{tabular}{|c|c|c|c|c|}
\hline \multirow[b]{2}{*}{ Unit } & \multirow[b]{2}{*}{$\mathrm{J}(\mathrm{Cl}-\mathrm{H} \mathbf{l})$} & \multirow{2}{*}{$\begin{array}{c}\text { Carbon } \\
\text { no. }\end{array}$} & \multicolumn{2}{|c|}{ Chemical shift (p.p.m.) } \\
\hline & & & Native & De- $O$-acetyl \\
\hline$\beta$-ManNAc & $162 \mathrm{~Hz}$ & $\begin{array}{l}1 \\
2 \\
3 \\
4 \\
5 \\
6\end{array}$ & $\begin{array}{l}98 \cdot 4 \\
55 \cdot 3 \\
73 \cdot 2 \\
79 \cdot 5 \\
77 \cdot 0 \\
62 \cdot 9\end{array}$ & $\begin{array}{l}98 \cdot 9 \\
55 \cdot 4 \\
73 \cdot 5 \\
79 \cdot 3^{*} \\
77 \cdot 5 \\
62 \cdot 7\end{array}$ \\
\hline$\beta$-ManNAcA & $162 \mathrm{~Hz}$ & $\begin{array}{l}1 \\
2 \\
3 \\
4 \\
5 \\
6\end{array}$ & $\begin{array}{c}100 \cdot 6 \\
52 \cdot 4 \\
77 \cdot 0 \dagger \\
71 \cdot 0 \\
77 \cdot 6 \dagger \\
176 \cdot 4\end{array}$ & $\begin{array}{c}101 \cdot 9 \\
52 \cdot 3 \\
79 \cdot 5^{*} \\
70 \cdot 0 \\
79 \cdot 8^{*} \\
177 \cdot 8\end{array}$ \\
\hline $\begin{array}{l}\text { N. } \mathrm{CO} \cdot \mathrm{CH}_{3} \\
\text { N.CO.CH}\end{array}$ & & & $\begin{array}{r}177 \cdot 4 \\
24 \cdot 7\end{array}$ & $\begin{array}{c}178 \cdot 2,178 \cdot 4 \\
24 \cdot 6,24 \cdot 8\end{array}$ \\
\hline $\begin{array}{l}\mathrm{O} . \mathrm{CO} \cdot \mathrm{CH}_{3} \\
\mathrm{O} . \mathrm{CO} \cdot \mathrm{CH}_{3}\end{array}$ & & & $\begin{array}{r}175 \cdot 2 \\
23 \cdot 2\end{array}$ & - \\
\hline & $\begin{array}{l}\text { *As } \\
+ \text { As }\end{array}$ & $\begin{array}{l}\text { may b } \\
\text { may b }\end{array}$ & $\begin{array}{l}\text { ged. } \\
\text { ged. }\end{array}$ & \\
\hline
\end{tabular}

Toxicity of extract antigens. When large amounts $(5 \mathrm{mg})$ of CAP were injected intravenously into three rabbits, the resulting rectal temperature increases were small $\left(0 \cdot 6,0 \cdot 2\right.$ and $\left.0 \cdot 3{ }^{\circ} \mathrm{C}\right)$. This contrasted with results obtained using an endotoxin containing extract of $P$. haemolytica whole cells (CN4676, serotype A2) prepared by the phenol/water method of Westphal \& Jann (1965). This endotoxin-containing extract gave temperature rises of 1.0 and $1.4{ }^{\circ} \mathrm{C}$ in two animals which received only $0.5 \mu \mathrm{g}$ of material.

Also, in chick embryos, CAP was non-toxic and failed to kill six injected at doses of $2.5 \mathrm{mg}$ per egg. In contrast, the endotoxin preparation killed all embryos at doses of only $5 \mu \mathrm{g}$ per egg. Due to the very low toxicity of CAP in these assays, the purified polymer was not tested.

Limulus lysate assay. In a titration in which $18.6 \mathrm{pg}$ standard Escherichia coli endotoxin $\mathrm{ml}^{-1}$ was the final dilution capable of gelling Limulus lysate, $0.1 \mu \mathrm{g}$ purified polymer $\mathrm{ml}^{-1}$ was required to produce gelatin. [This low gelling ability may be produced by highly purified polysaccharides in the absence of endotoxin (Mikami et al., 1982).]

Serological properties. In immunodiffusion experiments, antiserum raised in sheep to the partially purified polymer (CAP of Fig. 1) precipitated with antigens derived from A1 serotype organisms or culture supernatants only. Antigens prepared from several other serotypes of $P$. haemolytica (i.e. A2, T3, T4, A6, A7, T10) either by hot saline extraction of whole cells or by solvent extraction of culture supernates did not precipitate with the antiserum. Conversely hyperimmune antisera prepared in rabbits with $P$. haemolytica (washed whole organisms) precipitated with the purified polymer only when Al serotype organisms were used as the immunogen. Similarly, in passive haemogglutination experiments, erythrocytes coated with purified polymer were agglutinated by sheep antiserum to the polymer or to serotype A1 whole organisms, but were not agglutinated by antisera prepared in rabbits using $P$. haemolytica organisms or extracts of serotypes other than the A1.

Comparison of the serological cross-reactivity of extracts prepared by different methods from serotype Al organisms showed that saline or sodium salicylate extracts contained the same antigenic specificity as that present in the purified polymer. This was demonstrable both by immunodiffusion experiments, in which a line of identity was observed, and by the fact that erythrocytes coated with saline-, sodium salicylate- or solvent-derived extracts haemagglutinated to the same titre with a standard Al antiserum raised in rabbits against washed whole organisms. 


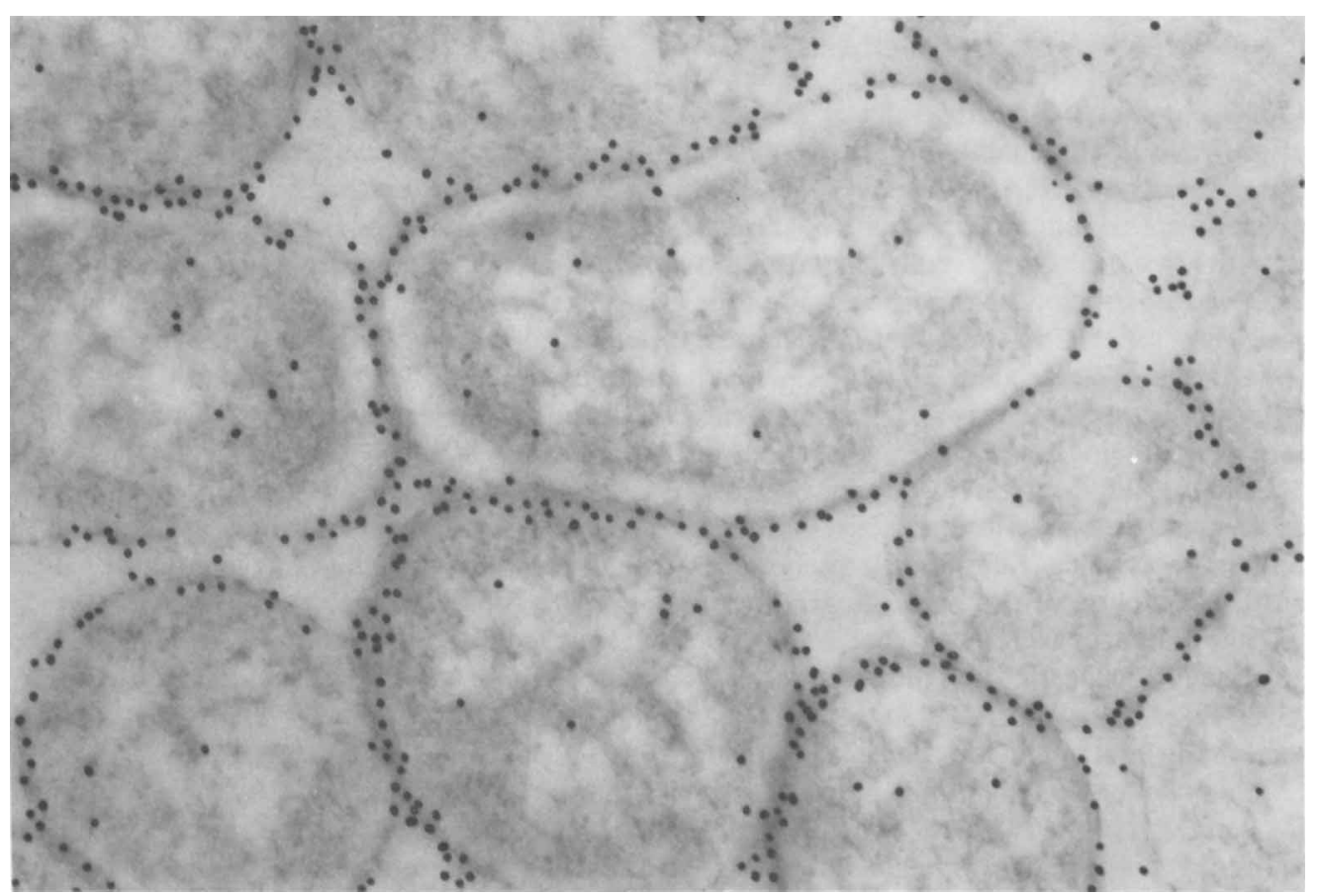

Fig. 4. Electron micrograph of sections of cells of strain P1075 previously incubated with antiserum raised against purified polymer in sheep and labelled with Protein A-gold. Peripheral localization of label is apparent. Magnification $\times 52000$.

In immunodiffusion experiments, reduction, oxidation or de- $O$-acetylation of the purified polymer did not significantly alter the precipitating properties of the material with specific antisera, although some spurring of the de- $O$-acetylated polymer with purified polymer was apparent. In contrast, these treatments completely destroyed the purified polymer's ability to adhere to sheep erythrocytes and cause passive haemagglutination with specific antisera. De- $N$ acetylation of the purified polymer destroyed both precipitation and erythrocyte-adherance properties.

Immune electron microscopy. Use of the Protein A-gold technique and sheep antiserum raised against the purified polymer showed the localization of the antigen to be at the cell periphery (Fig. 4).

\section{DISCUSSION}

Using the relatively simple solvent extraction procedure previously employed to produce nontoxic, protective extracts from P. multocida types B and E (Nagy \& Penn, 1974; Penn \& Nagy, 1976), it was possible to produce partially purified and essentially endotoxin-free capsular polysaccharide from culture supernatants of $P$. haemolytica serotype A1 organisms. Further purification with a method used by Gotschlich et al. (1972) to purify meningococcal capsular polysaccharides (partition in phenol/water, high speed centrifugation, re-precipitation in ethanol and molecular sieving) yielded a highly purified polymer, the structure of which could be completely resolved.

Experiments using amino-acid analysis, HPLC and TLC which showed the presence of 2amino-2-deoxy-mannose (mannosamine) in the polymer were critical to the initial interpretation of the ${ }^{13} \mathrm{C}$ NMR data. The defined peak 2 (Fig. 3) observed on the amino-acid analyser was probably produced by a disaccharide unit, since disaccharides of hexosamines and amino- 
hexuronic acids are relatively stable to the acid conditions used for hydrolysis, in contrast to the aminohexuronic acids themselves, which were highly labile (Wu \& Park, 1971; Liau et al., 1974). The fact that hydrolysates of the reduced polymer gave rise to barely detectable amounts of peak 2 is in agreement with the proposed formula of the polymer, which on reduction would become poly-ManNAc, with every alternate sugar being $O$-acetylated at the 4 position. On hydrolysis, this reduced polymer would only give rise to a 2-amino-2-deoxymannose peak rather than the two peaks observed with hydrolysates of the unreduced polymer. The low value of $61 \%$ for 2-amino-2-deoxy mannose obtained on analysis of the reduced and hydrolysed polymer probably reflects in part the difficulties inherent in satisfactorily hydrolysing polymers containing $\mathrm{N}$-acetylated 2-amino-2-deoxyhexose units (Lindberg \& Lonngren, 1978). In addition, IR spectroscopy showed that some unreduced carboxyl groups were still present in the sample following three cycles of carbodi-imide and borohydride.

Both of the component sugars (2-acetamido-2-deoxymannopyranose and 2-acetamido-2deoxymannopyranosyluronic acid) which make up the polysaccharide have been found in the cell wall polysaccharides and lipopolysaccharides of several bacteria (Yoneyama et al., 1982), but the structure of the present carbohydrate appears to be unique.

The polysaccharide was shown by electron microscopy using Protein A-gold labelled antibody to be localized on the periphery of the bacterial cell. Other electron microscope studies (Beesley et al., 1982) have suggested that this peripheral localization seen in methacrylate sections is equivalent to a capsule.

The polymer was immunogenic in sheep but not in rabbits. Similar observations were made by Penn \& Nagy (1976) for their partially purified $P$. multocida type B antigen, which was immunogenic in calves but not in rabbits. Immunodiffusion and passive haemagglutination experiments showed the purified polysaccharide to be specific to the Al serotype of $P$. haemolytica.

The observation that reduction, periodate treatment or de- $O$-acetylation of the polymer did not significantly alter its precipitability with immune sera ruled out the possibility that the $-\mathrm{COOH}$ group of the 2-acetamido-2-deoxymannuronic acid moiety and the $O$-acetyl group on the 4 position of this sugar had a role to play in immune precipitation. The $N$-acetyl groups on both sugars appeared to be involved in this process, however, as NMR studies showed them to be unaffected by these chemical treatments. When $N$-acetyl groups were removed chemically, precipitation of the resulting polymer with specific antisera was abolished. All chemical treatments destroyed the ability of the polymer to absorb to sheep erythrocytes and this was at first thought to be due to the loss of hydrolytically labile $O$-acetyl groups which were absent from NMR spectra of reduced, de- $O$-acetylated and de- $N$-acetylated samples. The spectrum for the periodate treated polymer did not, however, show any significant loss of $O$-acetyl groups and the reason for the failure of polymer treated in this way to adhere to red cells remains unexplained.

Interestingly, antiserum raised against the purified polymer also reacted with a line of 'identity' with sodium salicylate and sodium chloride extracts of $P$. haemolytica A 1 whole cells in immunodiffusion experiments. Since vaccines using sodium salicylate extracts are protective in lambs (Gilmour et al., 1979) and mice (Donachie et al., 1982), it will be important to determine whether the purified polysaccharide described above is also protective. Recent partial purification of a salicylate extract of $P$. haemolytica by Donachie et al. (1982) gave rise to a lipopolysaccharide rather than a polysaccharide. This could indicate that when present in the cell wall, the capsular polysaccharide is attached to lipid.

The excellent technical assistance of Christine Taylor, Anne Orpin, P. A. G. Roberts, R. N. Lucken, Linda Carpenter and the use of the Bruker WM-400 NMR instrument at Queen Mary College, University of London, through the courtesy of Dr G. E. Hawkes is gratefully acknowledged. The authors are grateful to Dr A. S. Gilbert for infra-red analysis and to $\operatorname{Dr} M$. R. Lifely for useful discussions.

\section{REFERENCES}

Beesley, J. E., Orpin, A. \& Adlam, C. (1982). A comparison of immunoferritin, immuno-enzyme and gold-labelled protein A methods for the localisa- tion of capsular antigen on frozen thin sections of the bacterium Pasteurella haemolytica. Histochemical Journal 14, 803-810. 
BENNETT, L. G. \& Bishop, C. T. (1980). Structure of the type XXXIII Streptococcus pneumoniae (pneumococcal) capsular polysaccharide. Canadian Journal of Chemistry 58, 2724-2727.

Bhattacharjee, A. K., Jennings, H. J., KenNy, C. P., Martin, A. \& Smith, I. C. P. (1975). Structural determination of the sialic acid polysaccharide antigens of Neisseria meningitidis serogroups B and C with carbon 13 nuclear magnetic resonance. Journal of Biological Chemistry 250, 1926-1932.

Bock, K. \& Thøgerson, H. (1982). Nuclear magnetic resonance spectroscopy in the study of mono and polysaccharides. Annual Reports of NMR Spectroscopy 13, 1-57.

Bundle, D. R., Jennings, H. J. \& Smith, I. C. P. (1973). The carbon-13 nuclear magnetic resonance spectra of 2-acetamido-2-deoxy-D-hexoses and some specifically deuterated, $O$-acetylated and phosphorylated derivatives. Canadian Journal of Chemistry 51, 3812-3819.

Dische, Z. (1947). A new specific color reaction of hexuronic acids. Journal of Biological Chemistry 167, 189-198.

DiXoN, J. S. \& LIPKIN, D. (1954). Spectrophotometric determination of vicinal glycols. Application to the determination of ribofuranosides. Analytical Chemistry 26, 1092-1093.

Donachie, W., Gilmour, N. J. L. \& Poxton, I. R. (1982). Cell surface antigens of Pasteurella haemolytica: characterization of the protective antigen in a mouse model. Society for General Microbiology Quarterly 9, M13.

Dubois, M., Gilles, K. A., Hamilton, J. K., Rebers, P. A. \& SMITH, F. (1956). Colorimetric method for the determination of sugars and related substances. Analytical Chemistry 28, 350-356.

Fraser, J., Lairds, S. \& Gilmour, N. J. L. (1982). A new serotype (biotype T) of Pasteurella haemolytica. Research in Veterinary Science 32, 127-128.

GaRdell, S., HejukenskJold, F. \& Rochnorlund, A. (1950). Oxidation of glucosamine and galactosamine with ninhydrin to arabinose and lyxose and their identification with paper chromatography. Acta chemica scandinavica 4, 970.

Gilmour, N. J. L., Martin, W. B., Sharp, J. M., Thompson, D. A. \& Wells, P. W. (1979). The development of vaccines against pasteurellosis in sheep. Veterinary Record 111, 15.

GoRIN, P. A. J. (1981). Carbon-13 nuclear magnetic resonance spectroscopy of polysaccharides. $A d$ vances in Carbohydrate Chemistry and Biochemistry 38, 13-104.

Gotschlich, E. C., Rey, M., Etienne, J., Sanborn, W. R., Priau, R. \& Cvjetanovic, B. (1972). The immunological responses observed in field studies in Africa with Group A meningococcal vaccine. Progress in Immunobiological Standardization 5, 485491.

Goustin, A. S., Krick, T. P. \& ANDERSON, J. S. (1983). Use of proton n.m.r. spectroscopy for detection of 2acetamido-2-deoxy-D-mannose- and 2-acetamido-2deoxy-D-mannuronate-containing carbohydrates. Carbohydrate Research 119, 258-262.

HANSEN, S. (1975). Thin layer chromatographic method for the identification of mono-, di- and trisaccharides. Journal of Chromatography 107, 224 226.
HeSTRIN, S. (1949). The reaction of acetylcholine and other carboxylic acid derivatives with hydroxylamine, and its analytical application. Journal of Biological Chemistry 180, 249-261.

Horton, D., Philips, K. D. \& Defaye, J. (1972). The nitrous acid deamination of 2-amino-2-deoxy-Dmannose hydrochloride to D-glucose. Carbohydrate Research 21, 417-419.

JANSSON, P. E., LINDBERG, B. \& LINDQUIST, U. (1981). Structural studies of the capsular polysaccharides from Streptococcus pneumoniae type 4. Carbohydrate Research 95, 73-80.

Johnson, S. D., Lacher, K. P. \& Anderson, J. S. (1981). Carbon-13 nuclear magnetic resonance spectroscopic study of the teichuronic acid from Micrococcus luteus cell walls. Comparison of the polysaccharide isolated from cells with that synthesised in vitro. Biochemistry 20, 4781-4785.

KENNE, L. \& LINDBERG, B. (1980). $N$-Deacetylation of polysaccharides. Methods in Carbohydrate Chemistry 8, 295-296.

LANE SMITH, R. \& GiLKERSON, E. (1979). Quantitation of glycosaminoglycan hexosamine using 3-methyl-2benzothiazolone hydrazone hydrochloride. Analytical Biochemistry 98, 478-480.

Liau, D. F., Melly, M. A. \& Hash, J. H. (1974). Surface polysaccharide from Staphylococcus aureus $\mathbf{M}$ that contains taurine, $\mathrm{D}$-aminogalacturonic acid, and D-fucosamine. Journal of Bacteriology 119, 913922.

LindBerg, B. \& LoNngren, G. (1978). Methylation analysis of complex carbohydrates: general procedure and application for sequence analysis. Methods in Enzymology 50, 3-33.

Mikami, T., Nagase, T., Matsumoto, T., Suzuki, S. \& SUzUKI, M. (1982). Gelation of Limulus amoebocyte lysate by simple polysaccharides. Microbiology and Immunology 26, 403-409.

MorRIS, G. A. \& FreEMAN, R. (1979). Enhancement of nuclear magnetic resonance signals by polarization transfer. Journal of the American Chemistry Society 101, 760-762.

NAGY, L. K. \& PENN, C. W. (1974). Protective antigens in bovine pasteurellosis. Developments in Biological Standardization 26, 25-32.

PenN, C. W. \& NaGY, L. K. (1976). Isolation of a protective, non toxic capsular antigen from Pasteurella multocida, types B and E. Research in Veterinary Science 20, 90-96.

Perry, M. B., Daoust, V. \& Carlo, D. J. (1981). The specific capsular polysaccharide of Streptococcus pneumoniae type 9V. Canadian Journal Biochemistry 59, 524-533.

ROE, J. H. (1955). The determination of sugar in blood and spinal fluid with anthrone reagent. Journal of Biological Chemistry 212, 335-343.

SPIRo, R. G. (1966). Analysis of sugars found in glycoproteins. Methods in Enzymology 8, 43-49.

STOFFYN, P. J.\& JEANLOZ, R. W. (1954). Identification of amino sugars by paper chromatography. Archives of Biochemistry and Biophysics 52, 373-379.

SVENNERHOLM, L. (1957). Quantitative estimation of sialic acids II. A colorimetric resorcinol-hydrochloric acid method. Biochimica et biophysica acta 24, 604-611.

TAYLOR, R. L. \& ConRAD, H. E. (1972). Stoichiometric depolymerization of polyuronides and glycosamino- 
glycuronans to monosaccharides following reduction of their carbodiimide-activated carboxyl groups. Biochemistry 11, 1383-1388.

Tsui, F.-P., Boykins, R. A. \& Egan, W. (1982). Structural and immunological studies of the Escherichia coli K7 (K56) capsular polysaccharide. Carbohydrate Research 102, 263-271.

TSUi, F.-P., SCHNeERSON, R. \& EgAN, W. (1981a). Structural studies of the Haemophilus influenzae type $\varepsilon$ capsular polysaccharide. Carbohydrate Research 88 , 85-92.

TSul, F. -P., SCHNEERSON, R., Boykins, R. A., KarPas, A. B. \& EgAN, W. (1981 b). Structural and immunological studies of the Haemophilus influenzae type d capsular polysaccharide. Carbohydrate Research 97, 293-306.
WARREN, L. (1959). The thiobarbituric acid assay for sialic acids. Journal of Biological Chemistry 234, 1971-1975.

WestPHAL, O. \& JANN, K. (1965). Bacterial lipopolysaccharides. Extraction with phenol-water and further applications of the procedure. Methods in Carbohydrate Chemistry 5, 83-92.

WU, T. C. M. \& PARK, J. T. (1971). Chemical characterization of a new surface antigenic polysaccharide from a mutant of Staphylococcus aureus. Journal of Bacteriology 108, 874-884.

Yoneyama, T., Koike, Y., ARakawa, H., Yokoyama, K., Sasaki, Y., Kawamura, T., ARaki, Y., Ito, E. \& TAKAO, S. (1982). Distribution of mannosamine and mannosaminuronic acid among cell walls of Bacillus species. Journal of Bacteriology 149, 15-21. 